\title{
OPEN A new long-term sampling approach to viruses on surfaces
}

\author{
Julia Sommer $^{1 凶}$, Martin Bobal ${ }^{1,3}$, Birgit Bromberger ${ }^{1}$, Patrick-Julian Mester ${ }^{1}$ \& \\ Peter Rossmanith ${ }^{1,2}$
}

The importance of virus disease outbreaks and its prevention is of growing public concern but our understanding of virus transmission routes is limited by adequate sampling strategies. While conventional swabbing methods provide merely a microbial snapshot, an ideal sampling strategy would allow reliable collection of viral genomic data over longer time periods. This study has evaluated a new, paper-based sticker approach for collection of reliable viral genomic data over longer time periods up to 14 days and after implementation of different hygiene measures. In contrast to swabbing methods, which sample viral load present on a surface at a given time, the paper-based stickers are attached to the surface area of interest and collect viruses that would have otherwise been transferred onto that surface. The major advantage of one-side adhesive stickers is that they are permanently attachable to a variety of surfaces. Initial results demonstrate that stickers permit stable recovery characteristics, even at low virus titers. Stickers also allow reliable virus detection after implementation of routine hygiene measures and over longer periods up to 14 days. Overall, results for this new sticker approach for virus genomic data collection are encouraging, but further studies are required to confirm anticipated benefits over a range of virus types.

The importance of virus disease outbreaks is of growing public concern. While viral epidemics and pandemics caused by Ebola, MERS-CoV and the current SARS-CoV-2 are most likely temporary events ${ }^{1,2}$, food-borne disease outbreaks as well as annual influenza outbreaks pose enduring threats to human health ${ }^{3,4}$. However, regardless of the viral pathogen, virus detection and determination of transmission routes are still poorly understood, largely because of inadequate sampling and monitoring tools. Until now the gold standard for virus detection, especially for infectious viruses, has been the plaque assay ${ }^{5,6}$. However, for verification purposes, growth-dependent assays are cost and time intensive and are not suitable for all viruses ${ }^{7}$. Consequently, there has been a drive for other, growth-independent detection methods for rapid virus detection ${ }^{7,8}$.

In general, virus detection in the food industry and healthcare settings is mostly performed by molecular methods, especially polymerase chain reaction (PCR) techniques ${ }^{9,10}$. However, swab sampling is still accepted as the method of choice ${ }^{11}$. Extensive surface sampling is not only relevant for detecting viral pathogens, but also for the demonstration of contamination routes, contamination sources and for monitoring persistent viruses in different environments ${ }^{12-14}$.

As viruses are able to endure in bacterial biofilms and remain infectious over long periods, their persistence in food facilities, hospitals and other institutions has been suspected to be a recurring cause of disease outbreaks ${ }^{15,16}$. Although swabbing methods are easy to perform, much effort has been expended to obtain more than merely a momentary, microbial snapshot from surfaces. Primarily, the sampling time point is not trivial as flushing, cleaning and disinfection can blur the actual viral load in multiple ways ${ }^{17}$. Since hygiene measures are essential to minimize pathogen transmission, ideally sampling approaches must overcome this limitation, which is essentially information loss ${ }^{17}$. Moreover, long-term virus monitoring strategies have likewise been neglected. Resolution of these major limitations requires novel, innovative sampling approaches to enable virus traceability and, simultaneously, increased safety.

This study focused on the evaluation of a new paper-based sticker approach for detection of viruses on surfaces over extended time periods. Recently Bobal and Witte et al. ${ }^{18}$ demonstrated the advantages of this sticker technique for detection and monitoring of bacterial pathogens on surfaces, including door handles. However, its utility for virus surface sampling has yet to be investigated. The main advantage of this new technique is its

\footnotetext{
${ }^{1}$ Unit of Food Microbiology, Institute of Food Safety, Food Technology and Veterinary Public Health Department for Farm Animals and Public Health in Veterinary Medicine, University of Veterinary Medicine, Veterinärplatz 1, 1210 Vienna, Austria. ${ }^{2}$ Joint BioEnergy Institute, Lawrence Berkeley National Laboratory, Berkeley, USA. ${ }^{3}$ Present address: Vetfarm and Clinical Unit of Herd Health Management for Ruminants, Department for Farm Animals and Public Health in Veterinary Medicine, University of Veterinary Medicine, Kremesberg 14, 2563 Pottenstein, Austria. ${ }^{\square}$ email: julia.sommer@vetmeduni.ac.at
} 


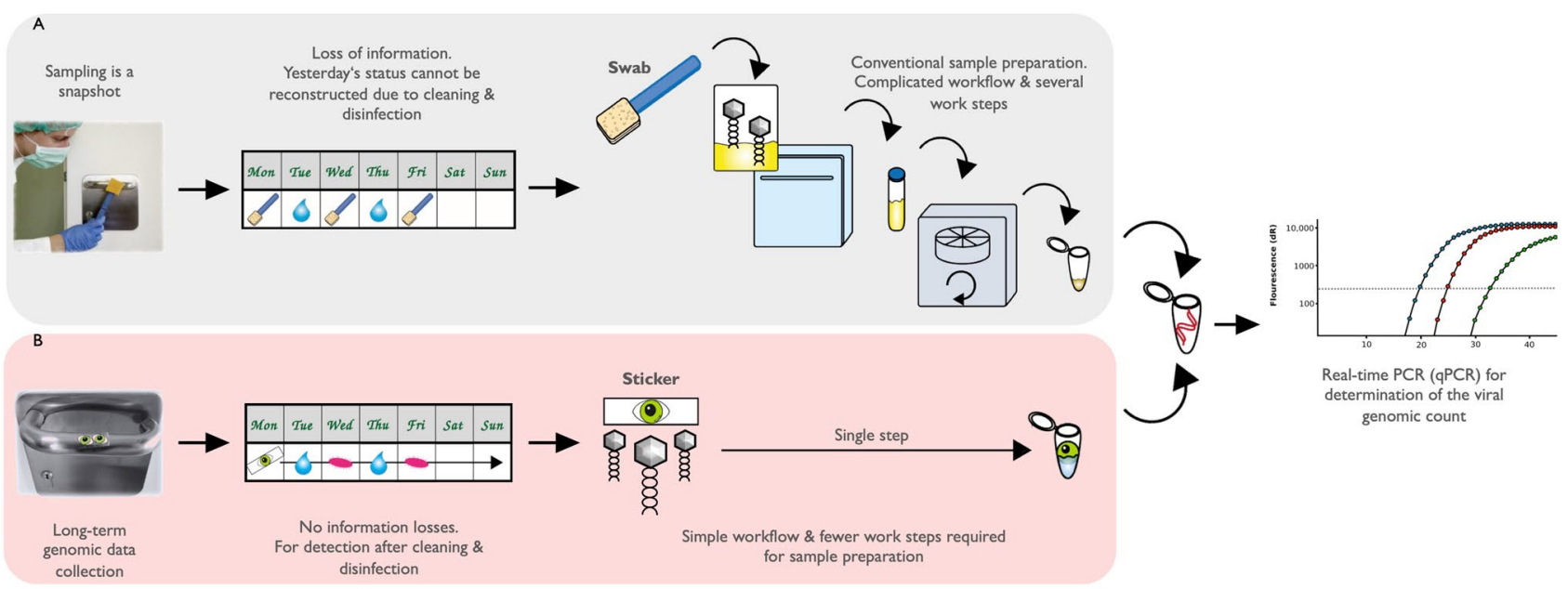

Figure 1. This figure depicts surface sampling procedures using common swabs (A) and paper-based adhesive stickers (B). While conventional swabbing before and after each hygiene step is required for reliable results longterm, the sticker approach requires only one self-adhesive sticker, which can be easily applied to a wide variety of surfaces. The sticker approach $(\mathbf{B})$ also provides a simple workflow and fewer steps than conventional swab sampling (A) prior to qPCR analysis.

simplicity, as shown in Fig. 1. The novel, essential feature of one-side adhesive paper-based stickers is that they can be easily applied to the majority of surfaces, where they collect viral particles that would be otherwise have been transferred onto that surface. Permanent application of the sticker to surfaces permits collection of viral genomic data over extended time periods, during which routine hygiene measures can continue to be practiced. Unlike common swabs, this new sampling approach does not reflect the current microbial load on a surface at a certain point of time, but due to its collection capacity it is suitable for long-term monitoring issues. Additionally, the sticker microbial sample can be easily extracted in one step (shown in Fig. 1), compared to conventional swab sampling that necessitates several preparation steps prior to detection using qPCR. Therefore, this new sampling approach offers a new and novel way of virus sampling and monitoring with minimized effort. However, in order to exploit the simplicity and expeditious characteristics of this sampling, a detailed analysis of sticker properties for virus collection is required. We evaluated recovery of infectious virus particles, the linear recovery properties of stickers, the recovery rate of viral genomic material after implementation of different hygiene measures such as cleaning and disinfection, and stability for up to 14 days.

\section{Results and discussion}

Until now virus transmission routes have been difficult to track due to a lack of adequate sampling strategies. Most of these employ swabs for virus uptake, which merely capture a momentary snapshot, and which are strongly influenced by hygiene measures that contribute to lost microbial information. Although a momentary snapshot of a surface is sufficient for virus detection, this type of sampling does not allow an all-encompassing recording of data over a longer period of time. So far novel long-term surface monitoring strategies and sampling materials for virus data collection are being rarely described ${ }^{19}$, this study focuses on evaluation of a new sampling approach that is both simple and based on existing material-the plain paper-based sticker. Both microbiological and molecular biological methods have been used to evaluate the benefits of this new paper-based sampling material for virus collection. As to this date no comparable sampling and monitoring approach to the recently invented paper-based sticker exists, we had to compare the routine cotton swabs and the sticker approach to each other, although a direct comparison is unsuitable, due to the fact that the new sticker approach will collect viral particles that would be otherwise have been transferred onto that entire surface of interest. In order to ensure an adequate evaluation of the new paper-based sticker, a comparison of a well-known sampling material was necessary. As the cotton swab is one of the best-known sample materials, it was chosen to clearly define the benefits of the new sticker sampling method and to determine its limitations. However, a clear separation of both methods is important, as their application and relating thereto-informative value strongly related to the question and issue posed by the user.

Recovery of infectious virus particles and determination of the linear and long-term monitoring properties of stickers. We initially compared the paper sticker sampling methods for infectious virus particles using plaque assays, the contemporary diagnostic gold standard ${ }^{5,6}$. The quantity of infectious virus particles (plaque forming units $(\mathrm{PFU}) / 100 \mu \mathrm{L}$ ) of artificially contaminated stickers and swabs was determined. Results presented in Table S1 indicate that neither cotton swabs nor stickers achieved reliable recovery rates of infectious viral particles over a broad concentration range. Indeed, the $8 / 8$ positive stickers or swabs score was only achievable using the two highest concentrations of virus solutions $\left(10^{8}\right.$ and $\left.10^{7} \mathrm{PFU} / 100 \mu \mathrm{L}\right)$; results presented in Fig. 2A and Table S1. This outcome is not surprising as the difficulties experienced in determining infectious virus particles from swab material has already been described in the literature, whereas the quantity of 

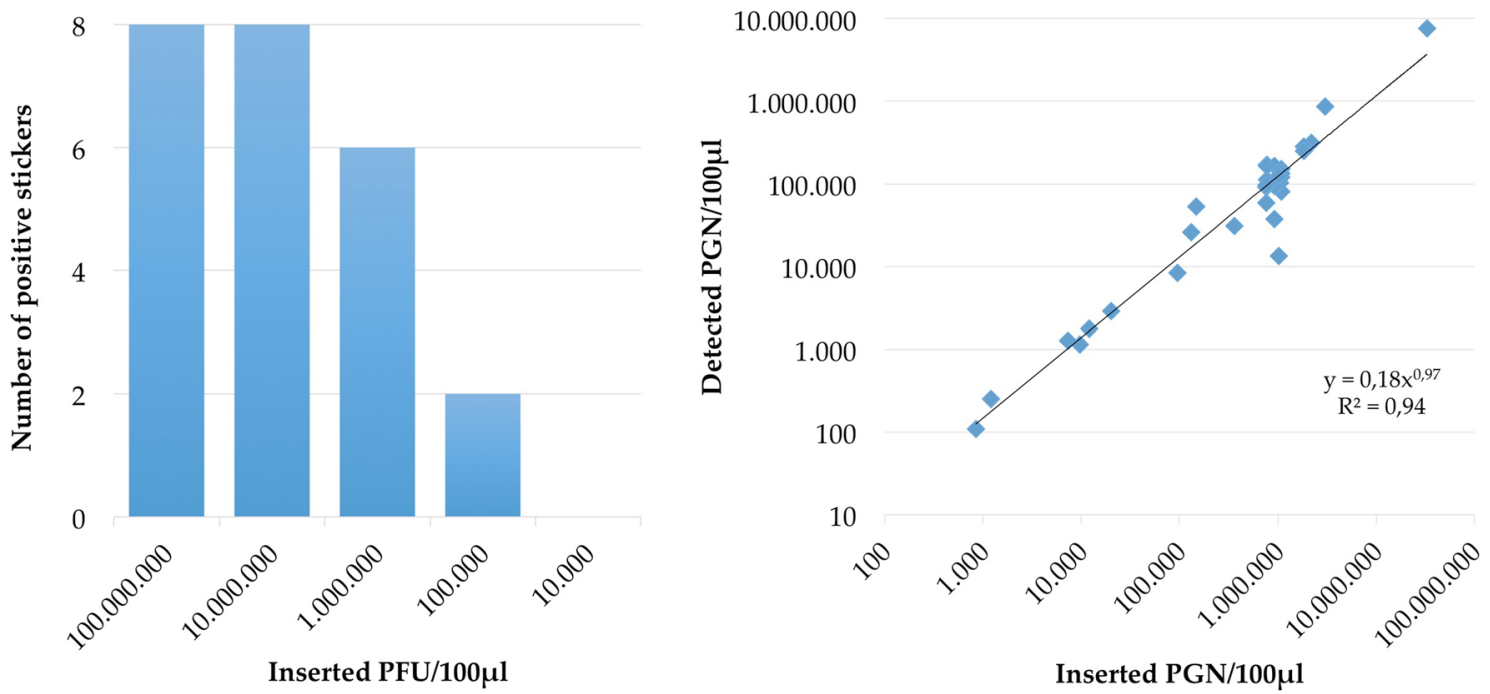

Figure 2. (A) The number of positive findings of eight sticker values and swab values determined by plaque assay from four independent experiments performed in duplicate. Virus titer concentrations ranging from $10^{8}$ to $10^{4}$ were used for artificial, direct contamination of paper-based stickers and routine cotton swabs. (B) The quantification of artificially contaminated plain-paper stickers $(n=32)$ with virus $P 100$. The sampling material was contaminated with known virus titers ranging from $10^{8}$ to $10^{2} \mathrm{PGN} / 100 \mu \mathrm{L}$ to cover a broad recovery range. The $\mathrm{x}$-axis plots the inserted quantity of viral genomic matter (PGN/100 $\mu \mathrm{L})$ and the $y$-axis plots the recovered viral genomic matter from respective sampling materials.

recovered infectious particles correlates with sampling material characteristics, such as electrostatic charge and others $^{20,21}$. As the binding strength of a virus depends on its isoelectric point, the interaction between virus and sampling material must be determined for each virus individually ${ }^{20,21}$. Alternatively, poor recovery can be a consequence of the inactivating effect of the sampling material itself; inactivation of virus particles on filter papers has already been demonstrated by Picard-Meyer and Cliquet ${ }^{22}$. Nevertheless, the interactions of virus P100 and sticker material was beyond the scope of this study.

Although sampling materials recovered similar quantities of infectious virus particles, growth-dependent verification is disadvantaged in respect of its detection limit. The detection limit for virus P100 with the plaque assay was approximately $10^{4} \mathrm{PFU} / 100 \mu \mathrm{L}$ (Fig. 2; Table S1). This is a relatively high concentration and it prompted us to use qPCR instead.

To investigate the broad range linearity of detection of this new approach, the stickers were spike-inoculated with virus concentrations ranging from $10^{8}$ to $10^{2}$ phage genome number (PGN)/100 $\mu \mathrm{L}$ and the viral load was determined using qPCR. The same protocol was used for the swabs, which were directly compared. As shown in Fig. 2B the stickers achieved a coefficient of determination of 0.94 , which is in good accordance with 0.98 obtained for swabs (Figure S1). This represents good linear detection properties over a broad viral concentration range for both sampling materials. Stickers and swabs also achieved similar virus recovery rates over a broad virus concentration range; stickers had a mean recovery of $15 \%$ and swabs $18 \%$ (Table S2), also at lower concentrations of about $10^{2} \mathrm{PGN} / 100 \mu \mathrm{L}^{23}$. These outcomes are highly relevant as they demonstrate that stickers have comparable sensitivity to the current virus sampling system.

As Cardona-Ospin et al. ${ }^{24}$ have demonstrated the efficacy of paper-based filters for preservation of viral RNA, we investigated the long-term characteristics of stickers and whether they were suitable for collection of viral genomic matter over longer time periods. Stickers were inoculated with a known virus suspension and the detectable genomic viral load after 0, 1, 3, 7 and 14 days was determined. Results are presented in the supplement Figure S2 and indicate that the viral load remains constant until day 7. After 14 days of incubation a slight decrease could be observed. However, these results confirm that long-term monitoring of viral genomic loads is possible with paper-based stickers.

Viral DNA recovery from stickers and the effect of hygiene measures. As the paper-based stickers exhibited good linear and long-term monitoring properties, we quantified viral genomic material after implementation of various surface hygiene measures. Sterile ceramic tiles were used as experimental surfaces. Stickers were applied to the tiles and surfaces contaminated with known concentrations of virus solution. After a drying phase of at least $1 \mathrm{~h}$, the surfaces were separately cleaned or disinfected with a variety of techniques. Five different hygiene measures were compared to cover as many routine procedures as possible, representing those commonly applied in food environments, hospitals and public places. Results presented in Fig. $3 \mathrm{~B}$ reveal, not unexpectantly, that swabs were associated with viral information losses ranging across the different treatments. While both C: I and II cleaning measures led to a decrease of one log 10 unit, the D: III disinfection measure resulted in a decrease of about $1.3 \log 10$ units. The highest viral reduction was achieved with combined treatments $\mathrm{C}$ and 
A

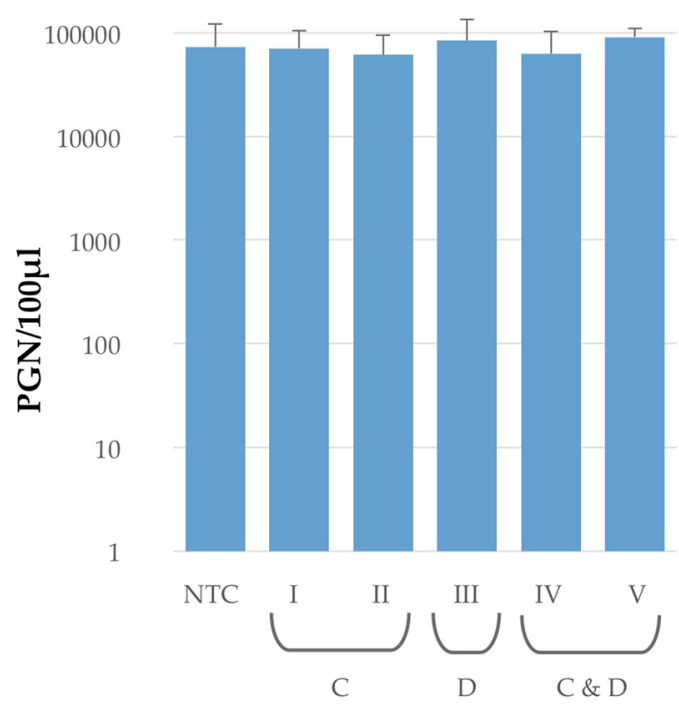

Treatment
B

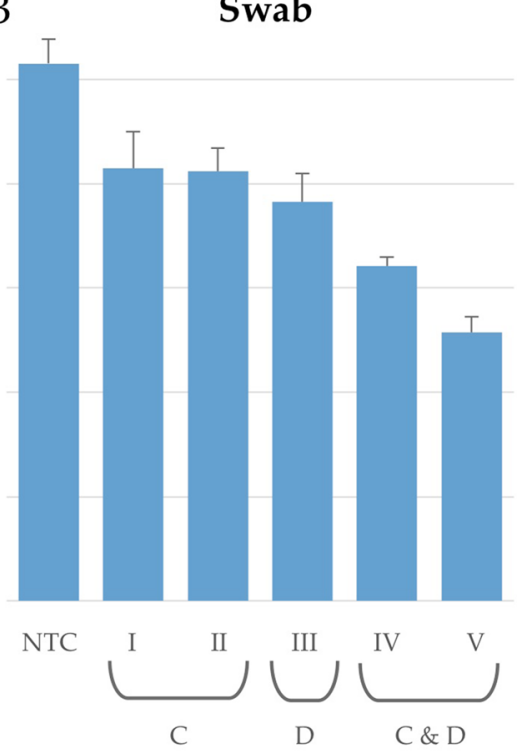

Treatment

Figure 3. Viral genome recovery rate after cleaning and disinfection of paper-based stickers and cotton swabs. Surfaces or stickers applied to surfaces were artificially contaminated with a concentration of approximately $10^{6}$ PGN/100 $\mu \mathrm{L}$. After drying, surfaces were treated with different methods, sampled, DNA extracted and analysed with qPCR. Treatments comprised a no treatment control (NTC), two cleaning treatments (C) (I) flush with water, (II) flushed with soapy water, the disinfection treatment (D) (III) wiped with Mirkozid and combined treatments (C and D) (IV) cleaning with BUDENAT ALKASEPT D 445 and wiped with Mikrozid, and (V) flushed with soapy water and wiped with Mikrozid. Each experiment was performed at least in triplicate and bars show mean values with respective standard deviations. Data were analysed using the Kruskal-Wallis test of independent samples.

D: IV and V, which were associated with reductions of 2-2.6 $\log 10$ units. In contrast to the swab results, sticker results in Fig. 3A show that the viral load remained constant over all investigated hygiene measures compared to the no treatment control (NTC). After direct comparison of each treatment as sticker versus swab, significant virus recovery differences between materials were observed after treatments (D: III), wiped with Mikrozid $\left({ }^{*} \mathrm{p} \leq 0.05\right)$, and C+D: IV, cleaning with BUDENAT ALKASEPT D 445 and wiped with Mikrozid $\left({ }^{*} \mathrm{p} \leq 0.05\right)$, and $\mathrm{V}$ flushed with soapy water and wiped with Mikrozid $\left({ }^{* *} \mathrm{p} \leq 0.001\right)$. Treatment $\mathrm{V}$ was most effective, which achieved a significance-value of ${ }^{* *} \mathrm{p} \leq 0.001$.

Considering the use of virus-inactivating treatments and electrostatic binding of virus particles to the paper stickers, recontamination events associated with the sticker itself can be excluded. However, confirmation will necessitate further investigations, using a range of viruses ${ }^{25}$. Overall, results indicate that the sticker approach was not associated with information losses that might be attributed to common hygiene measures. Further, results indicate that sticker sampling offers new opportunities for the identification of viral transmission hotspots and could provide further insight into viral transmission routes not available through "snapshot" swabbing approaches.

\section{Materials and methods}

Virus. Bacterial virus P100, purchased as PhageGuard Listex P100 solution (Batch 12G26, Lot: 308; Micreos, Wageningen, The Netherlands) was used in this study. For enumeration and propagation of phage P100 the related bacterial strain L. monocytogenes EGDe (ATCC BAA-679) was used. The bacteria were grown overnight at $37^{\circ} \mathrm{C}$ in tryptone soya broth (TSB) with $0.6 \%(w / v)$ yeast extract (Oxoid Ltd., Hampshire, UK). After overnight incubation, the bacterial culture was ten-fold diluted in fresh medium and incubated at $37^{\circ} \mathrm{C}$ for $3-4 \mathrm{~h}$ to obtain a maximum number of viable cells in the logarithmic growth phase (log phase). For propagation of virus stock, virus solutions were used for plaque assay, according to the protocol of Kropinski et al. ${ }^{26}$. Plates with confluent lyses were overlaid with $5 \mathrm{~mL}$ TSB or saline-magnesium (SM) buffer $(5.8 \mathrm{~g} \mathrm{NaCl}, 2.4 \mathrm{~g}$ Tris $\mathrm{HCl}, 1.0 \mathrm{~g}$ $\mathrm{CaCl}_{2}, 0.1 \mathrm{~g}$ gelatin, add $\left.1.0 \mathrm{~mL} \mathrm{H}_{2} \mathrm{O}, \mathrm{pH} 7.5\right)$ and shaken for about $3 \mathrm{~h}$ at room temperature or overnight at $4{ }^{\circ} \mathrm{C}$. Afterwards the medium was separated and centrifuged at $8000 \mathrm{rpm}$ for $2 \mathrm{~min}$. Finally, the supernatant was filtered $(0.02 \mu \mathrm{m})$, aliquoted and stored at $-20^{\circ} \mathrm{C}$.

Quantification of infectious virus particles on stickers. Virus P100 was used at stock concentrations of approximately $10^{10}-10^{8} \mathrm{PFU} / 100 \mu \mathrm{L}$. The investigated range of about $10^{8}-10^{4} \mathrm{PFU} / 100 \mu \mathrm{L}$ was based on a study of Herzog et al. ${ }^{27}$, which investigated virus P22 recovery efficiencies over a broad range of virus 
concentrations. Virus titers of artificially contaminated stickers, swabs and positive control were determined using the Small Drop Plaque Assay ${ }^{28}$. An overnight culture of L. monocytogenes EGDe was tenfold diluted in SM-buffer ${ }^{26,28}$ and subsequently a tenfold serial dilution from the aqueous-phase was prepared in bacteriacontaining buffer. After $30 \mathrm{~min}$ of incubation at $37^{\circ} \mathrm{C}, 20 \mu \mathrm{L}$ of each dilution were dropped onto a tryptone soya agar (TSA)-plate and incubated overnight at the strain-respective temperature of $37^{\circ} \mathrm{C}$. The next day plaques were counted and compared with untreated, positive controls. All plaque assay experiments were repeated at least twice in duplicate.

Viral DNA extraction. Each sticker was detached with sterile tweezers and transferred into a $1.5-\mathrm{mL}$ Eppendorf tube and overlaid with $200 \mu \mathrm{L}$ sterile water and thoroughly vortexed. The same procedure was performed with each swab sample and all positive and negative controls. Subsequently the DNA of each sample was isolated using the commercially available NucleoSpin tissue kit (Macherey Nagel, Düren, Germany) in accordance with the user manual (6.5 Support protocol for genomic DNA and viral DNA from blood samples) ${ }^{29}$. All experiments included a positive control (untreated phage-solution) and were repeated at least twice in duplicate or individually on three different days.

Numeration of viral genome using real time PCR (qPCR). For determination of the viral load $(\mathrm{PGN} / 100 \mu \mathrm{L})$, the isolated samples were analyzed with qPCR. The primers for virus P100 qPCR were chosen according to Fister et al. ${ }^{30}$ and qPCR assays were performed using the non-specific DNA-dye EvaGreen Dye (Jena Bioscience GmbH, Jena, Germany). One qPCR reaction of $25 \mu \mathrm{L}$ final volume contained $2.5 \mu \mathrm{L}$ of $10 \times$ reaction buffer (Biozym Scientific GmbH, Hessisch Oldendorf, Germany), $1.2 \mu \mathrm{M}$ of probe EvaGreen Dye, $200 \mu \mathrm{M}$ of each dNTPs (dATP, dTTP, dGTP and dCTP) and $1 \mathrm{U}$ of Taq DNA polymerase (Biozym Scientific GmbH, Hessisch Oldendorf, Germany). Each P100 primer (forward: AGCAGAGTTTGAAAAAATTGATGA CTAC and reverse: TCGTCATGCGTGTTTCTATGC), purchased from Eurofins Genomics (Ebersberg, Germany), was inserted to reach a final concentration of $500 \mathrm{nM}$. All qPCR assays were performed in an Mx3000 real-time PCR thermocycler (Stratagene, San Diego, CA, USA) with cycling conditions of 2 min at $94{ }^{\circ} \mathrm{C}, 45 \times$ $\left(30 \mathrm{~s} \text { at } 94^{\circ} \mathrm{C}, 30 \mathrm{~s} \text { at } 59^{\circ} \mathrm{C}, 30 \mathrm{~s} \text { at } 72{ }^{\circ} \mathrm{C}\right)^{30}$. The average efficiency of this qPCR was $99.6 \%$ and the average Rsq was 0.997 . All qPCR experiments were conducted as a PCR-duplicate and included a negative amplification control as well as a standard series for calculation of a standard curve, whereas the standard curve was used for quantification of the viral nucleic acids.

Artificial contamination of stickers, swabs and controls. Commercially available text-marking stickers (Markierungspunkte $\varnothing 8 \mathrm{~mm}$, permanent, no. 3013 yellow and 3175 white; Avery of CCL Industries, Inc., Toronto, Canada) were applied to an aseptic Petri dish $100 \mathrm{~mm} \times 15 \mathrm{~mm}$ (Corning Inc., New York, USA) using sterile tweezers. The transferred stickers were sterilized with UV-C radiation for at least $15 \mathrm{~min}$, as previously described by Bobal and Witte et al. ${ }^{18}$. Subsequently stickers were artificially contaminated or attached to the surface of interest for further experiments. Stickers and swabs were then contaminated with $5 \mu \mathrm{L}$ virus solution and dried for at least $1 \mathrm{~h}$. For the positive control the equi-volume of virus solution was transferred directly to $200 \mu \mathrm{L}$ water and DNA isolation was performed as described above (2.3. Viral DNA Extraction).

Cleaning and disinfection of surfaces. Different test conditions were chosen for the surface experiments. Each sterile ceramic tile $(5 \mathrm{~cm} \times 5 \mathrm{~cm})$ was artificially contaminated with $5 \mu \mathrm{L}$ virus solution, whereas the sticker was applied onto the tile before contamination. After a drying phase of at least $1 \mathrm{~h}$, the surfaces were treated with different cleaning and disinfection treatments: (NTC) without washing, (I) flush with water, (II) flush with soapy water, (III) wiped with Mikrozid, (IV) cleaned with BUDENAT ALKASEPT D 445 and wiped with Mikrozid, and (V) flushed with soapy water and wiped with Mikrozid. Unwashed tiles were used as positive, untreated controls. For the flush treatments, (I) with water and (II) soapy water, the tiles were flushed twice with $1 \mathrm{~mL}$ liquid, whereas the soapy water tile was additionally rinsed with $0.5 \mathrm{~mL}$ distilled water. The soapy water was prepared by diluting the household cleaner Exact AC (E. Mayr, Vösendorf, Austria) in water to provide concentrations commonly used for surface cleaning $(0.001-0.002 \%$ as described in the product data sheet). For treatment (III), disinfection of surfaces, Mikrozid AF liquid (Schülke \& Mayr, Norderstedt, Germany) was applied by wiping. Treatment IV), cleaning with BUDENAT ALKASEPT D 445 and wiped with Mikrozid, was provided as BUDENAT ALKASEPT D 445 (Buzil-Werk Wagner GmbH \& Co. KG, Memmingen, Germany), which is recommended as a high alkaline disinfectant cleaning agent for surface cleaning in food environments. For this treatment $1 \mathrm{~mL}$ of a 5\% BUDENAT ALKASEPT D 445 solution was added to the ceramic tile and incubated for $30 \mathrm{~min}$. Subsequently the tiles were rinsed with $0.5 \mathrm{~mL}$ water and wiped with Mikrozid. The last treatment, treatment $(\mathrm{V})$, comprised a combined treatment with treatments (II) and (III). After surface treatments the previously applied sticker was further treated as described in 2.3 Viral DNA Extraction. The swab sample was taken by moistening the cotton swab with $100 \mu \mathrm{L}$ SM-Buffer and afterwards the moistened swab was rubbed over the whole surface for $10 \mathrm{~s}$. Afterwards the samples were treated as described in 2.3 Viral DNA Extraction.

Controls, calculation of recoveries and statistical analysis. Recoveries from all experiments, determination of the PFU/100 $\mu \mathrm{L}$ (plaque assay) and the PGN/100 $\mu \mathrm{L}$ (qPCR) results were compared with those from the relevant positive controls. Further, sticker results were compared with corresponding swab results. Each experiment was repeated at least twice in duplicate, enabling calculation of average recovery and standard errors to account for variation of the data across means. Data were analysed using the Kruskal-Wallis test of independent samples from stickers and swabs $\left({ }^{*} \mathrm{p} \leq 0.05,{ }^{* *} \mathrm{p} \leq 0.01,{ }^{* * *} \mathrm{p} \leq 0.001\right)$. 


\section{Conclusions}

Current knowledge of virus transmission routes and virus persistence is limited by imperfect viral particle detection and long-term monitoring strategies. Consequently, this study has evaluated a new and easy-to-use sampling material, the paper-based sticker. This sticker has already been investigated in respect of bacterial sampling ${ }^{18}$, but its application to virus monitoring has remained uninvestigated. Single-sided adhesiveness means that stickers are attachable almost anywhere, including previously "difficult to access" areas and collect viral particles that would have otherwise been transferred onto the surface. Paper-based stickers also exhibit characteristics particularly suitable for long-term surface monitoring of viruses, unlike to swabs, which are made for the determination of actual viral load on a surface. These include a good linear binding capacity in terms of viral particles and viral DNA for up to 14 days, and resilience to routine cleaning and disinfection. Stable recovery rates of viruses from surfaces have also been demonstrated after various cleaning and disinfection measures without information loss. It is also unlikely that the stickers will have fomite properties as bound viruses remained non-infectious. In the future, various improvement options are to be tested in order to guarantee stable virus recoveries. While initial studies raise optimism for a new approach to surface virus monitoring, further studies are required to ascertain its suitability across a range of viruses, including enveloped and RNA viruses.

Patents. This article is intended to discuss, but not modify, Patent Application Publication No. WO 2020/182924 A1, titled 'A Novel Sampling Method for Long-Term Monitoring of Microbes', for the purpose of increasing the accessibility of the scientific content contained therein. Inventors: Martin Bobal, Anna Witte, Patrick Mester and Peter Rossmanith. Current Applicant: Merck Patent GmbH (Frankfurter Strasse 250, 64293 Darmstadt). Filed: 14 March 2019. Published: 17 September 2020. This patent application is in no way limited by the publication of this article. Readers interested in the specific intellectual property covered by this patent should review the patent at the link provided below. Readers may also contact the authors or Merck Patent $\mathrm{GmbH}$ for licensing information. https://patentscope.wipo.int/search/en/detail.jsf?docId=WO2020182924.

Received: 26 January 2021; Accepted: 4 August 2021

Published online: 02 September 2021

\section{References}

1. Reperant, L. A. \& Osterhaus, A. D. M. E. Aids, avian flu, sars, mers, ebola, zika... what next?. Vaccine 35, 4470-4474 (2017).

2. Hu, B., Guo, H., Zhou, P. \& Shi, Z.-L. Characteristics of sars-cov-2 and covid-19. Nat. Rev. Microbiol. 20, 20 (2020).

3. European Food Safety, A. \& European Centre for Disease, P.; Control. The European union summary report on trends and sources of zoonoses, zoonotic agents and food-borne outbreaks in 2017. EFSA J. 16, e05500 (2018).

4. Chatziprodromidou, I. P. et al. Global avian influenza outbreaks 2010-2016: A systematic review of their distribution, avian species and virus subtype. Syst. Rev. 7, 17 (2018).

5. Barardi, C. et al. Monitoring viruses in environmental samples. J. Environ. Sci. Eng. Technol. 3, $62-67$ (2012).

6. Hamza, I. A., Jurzik, L., Überla, K. \& Wilhelm, M. Methods to detect infectious human enteric viruses in environmental water samples. Int. J. Hyg. Environ. Health 214, 424-436 (2011).

7. Bosch, A. et al. Foodborne viruses: Detection, risk assessment, and control options in food processing. Int. J. Food Microbiol. 285 , 110-128 (2018).

8. Stephens, B. et al. Microbial exchange via fomites and implications for human health. Curr. Pollut. Rep. 5, 198-213 (2019).

9. Lowther, J. A. et al. Validation of en iso method 15216-part 1-quantification of hepatitis a virus and norovirus in food matrices. Int. J. Food Microbiol. 288, 82-90 (2019).

10. Turnage, N. L. \& Gibson, K. E. Sampling methods for recovery of human enteric viruses from environmental surfaces. J. Virol. Methods 248, 31-38 (2017).

11. Rodríguez-Lázaro, D. et al. Virus hazards from food, water and other contaminated environments. FEMS Microbiol. Rev. 36, 786-814 (2012).

12. Fallahi, S. \& Mattison, K. Evaluation of murine norovirus persistence in environments relevant to food production and processing. J. Food Prot. 74, 1847-1851 (2011).

13. Sommer, J. et al. Don't shut the stable door after the phage has bolted-the importance of bacteriophage inactivation in food environments. Viruses 11, 20 (2019).

14. Fister, S. et al. Part of the problem or the solution? Indiscriminate use of bacteriophages in the food industry can reduce their potential and impair growth-based detection methods. Trends Food Sci. Technol. 20, 20 (2019).

15. Jacques, M., Grenier, D. \& Labrie, J. Persistence of porcine reproductive and respiratory syndrome virus and porcine circovirus type 2 in bacterial biofilms. JSHAP 23, 132-136 (2015).

16. Skraber, S. et al. Occurrence and persistence of enteroviruses, noroviruses and f-specific rna phages in natural wastewater biofilms. Water Res. 43, 4780-4789 (2009).

17. Griffith, C. Surface sampling and the detection of contamination. Handb. Hygiene Control Food Ind. 20, 673-696 (2016).

18. Bobal, M. et al. A novel method for sampling and long-term monitoring of microbes using stickers of plain paper. Appl. Environ. Microbiol. 20, 85 (2019).

19. Kumar, P. K. R. Monitoring intact viruses using aptamers. Biosensors 6, 40 (2016).

20. Lee, C. et al. Comparison of swab sampling methods for norovirus recovery on surfaces. Food Environ. Virol. 20, 10 (2018).

21. Yeargin, T., Fraser, A., Huang, G. \& Jiang, X. Recovery and disinfection of two human norovirus surrogates, feline calicivirus and murine norovirus, from hard nonporous and soft porous surfaces. J. Food Prot. 78, 1842-1850 (2015).

22. Picard-Meyer, E., Barrat, J. \& Cliquet, F. Use of filter paper ( $\mathrm{fta}$ ) technology for sampling, recovery and molecular characterisation of rabies viruses. J. Virol. Methods 140, 174-182 (2007).

23. Minich, J. et al. Feasibility of Using Alternative Swabs and Storage Solutions for Paired SARS-COV-2 Detection and Microbiome Analysis in the Hospital Environment (Research Square, 2020).

24. Cardona-Ospina, J. A., Villalba-Miranda, M. F., Palechor-Ocampo, L. A., Mancilla, L. I. \& Sepúlveda-Arias, J. C. A systematic review of fta cards as a tool for viral rna preservation in fieldwork: Are they safe and effective?. Prev. Vet. Med. 172, 104772-104772 (2019). 
25. Scherer, K. et al. Application of a swab sampling method for the detection of norovirus and rotavirus on artificially contaminated food and environmental surfaces. Food Environ. Virol. 1, 42 (2009).

26. Kropinski, A., Mazzocco, A., Waddell, T., Lingohr, E. \& Johnson, R. Enumeration of bacteriophages by double agar overlay plaque assay. In Bacteriophages Vol 501 (eds Clokie, M. J. \& Kropinski, A.) 69-76 (Humana Press, 2009).

27. Herzog, A. et al. Evaluation of sample recovery efficiency for bacteriophage p22 on fomites. Appl. Environ Microbiol. 78, 7915-7922 (2012).

28. Mazzocco, A., Waddell, T., Lingohr, E. \& Johnson, R. Enumeration of bacteriophages using the small drop plaque assay system. In Bacteriophages Vol 501 (eds Clokie, M. J. \& Kropinski, A.) 81-85 (Humana Press, 2009).

29. Macherey-Nagel. Genomic DNA from tissue-user manual nucleospin tissue. http://www.mn-net.com/Portals/8/attachments/ Redakteure_Bio/Protocols/GenomicDNA/UM_gDNATissue.pdf. Accessed 06 Jan 2020.

30. Fister, S. et al. The use of ionic liquids for cracking viruses for isolation of nucleic acids. Sep. Purif. Technol. 155, 38-44 (2015).

\section{Acknowledgements}

We thank Anna Kristina Witte (HTK Hygiene Technologie Kompetenzzentrum GmbH, Bamberg, Germany) for her support and the creation of the Fig. 1. We also thank Birgit Bromberger for her support as a photo model.

\section{Author contributions}

P.R. and P.-J.M.: supervision and conceptualization; P.-J.M. and J.S.: methodology; J.S.: validation, data curation, visualization and writing — original draft; M.B., B.B. and J.S.: investigation; P.R.: project administration, resources and funding acquisition.

\section{Funding}

Open Access funding for this article was provided by the University of Veterinary Medicine Vienna (Vetmeduni Vienna). Financial support by the Austrian Federal Ministry for Digital and Economic Affairs and the National Foundation for Research, Technology and Development is gratefully acknowledged.

\section{Competing interests}

The authors declare no competing interests.

\section{Additional information}

Supplementary Information The online version contains supplementary material available at https://doi.org/ 10.1038/s41598-021-96873-9.

Correspondence and requests for materials should be addressed to J.S.

Reprints and permissions information is available at www.nature.com/reprints.

Publisher's note Springer Nature remains neutral with regard to jurisdictional claims in published maps and institutional affiliations.

(c) (i) Open Access This article is licensed under a Creative Commons Attribution 4.0 International License, which permits use, sharing, adaptation, distribution and reproduction in any medium or format, as long as you give appropriate credit to the original author(s) and the source, provide a link to the Creative Commons licence, and indicate if changes were made. The images or other third party material in this article are included in the article's Creative Commons licence, unless indicated otherwise in a credit line to the material. If material is not included in the article's Creative Commons licence and your intended use is not permitted by statutory regulation or exceeds the permitted use, you will need to obtain permission directly from the copyright holder. To view a copy of this licence, visit http://creativecommons.org/licenses/by/4.0/.

(c) The Author(s) 2021 